\title{
TREATMENT WITH RECOMBINANT GROWTH HORMONE IN CHILDREN WITH TURNER SYNDROME: A STUDY FROM A TERTIARY UNIVERSITY CENTER
}

\author{
Kamelia Rankova ${ }^{1}$, Violeta Iotova ${ }^{1}$, Vilhelm Mladenov ${ }^{1}$, Teodora Karamfilova ${ }^{1}$, \\ Yuliya Bazdarska ${ }^{1}$, Nikolinka Yordanova ${ }^{1}$, Irina Halvadzhiyan ${ }^{2}$, Mari Hachmeriyan ${ }^{3}$, \\ Yana Bocheva ${ }^{4}$, Veselin Boyadzhiev ${ }^{1}$, Sonya Galcheva ${ }^{1}$ \\ ${ }^{1}$ Department of Pediatrics, Faculty of Medicine, Medical University of Varna \\ ${ }^{2}$ Department of Pediatrics, Faculty of Medicine, Medical University-Pleven \\ ${ }^{3}$ Department of Medical Genetics, Faculty of Medicine, Medical University of Varna \\ ${ }^{4}$ Department of General Medicine and Clinical Laboratory, Faculty of Medicine, \\ Medical University of Varna
}

\begin{abstract}
INTRODUCTION: Turner syndrome (TS) is a rare disease with typical phenotype manifestations and short stature. Part of the therapy in TS patients is the recombinant human growth hormone (rhGH) that leads to improved height velocity and final height.

AIM: The aim of the current study is to summarize the results of the diagnosis and treatment with rhGH of the TS patients followed up at a tertiary university center from 2011 to 2020.

PATIENTS AND METHODS: The study design is a retrospective cohort evaluation. All study participants had at least one full year of observation at the center. A total of 28 children with genetically confirmed TS or TS variation karyotype, aged between 2 and 18 years, $92.9 \%$ of whom were girls, participated in the study.

RESULTS: The mean age at diagnosis was $9.6 \pm 3.7$ years. Therapy with rhGH was started at $9.27 \pm 3.4$ years in $22(78.5 \%)$ of them with a mean rhGH dose of $0.035 \pm 0.006 \mathrm{mg} / \mathrm{kg} / \mathrm{d}$, which led to height gain of $8.0 \pm 1.3$ $\mathrm{cm}$ for the first year. With a similar rhGH dose for the $2^{\text {nd }}$ year of treatment $(0.033 \pm 0.007 \mathrm{mg} / \mathrm{kg} / \mathrm{d})$, height velocity of $6.8 \pm 1.1 \mathrm{~cm}$ was achieved $(\mathrm{p}<0.005)$. A positive change in $\mathrm{SDS}_{\text {height }}$ was observed for the first year of therapy $(-2.75 \pm 1.2$ vs. $-2.27 \pm 1.2, \mathrm{p}=0.005)$. SDS $_{\text {IGF- }}$ before and after one treatment year increased significantly $(-0.74 \pm 1.1$ vs.1.57 $\pm 1.4, \mathrm{p}=0.001)$, without exceeding $2.0 \mathrm{SD}$.

CONCLUSION: The achieved growth in the presented TS cohort is suboptimal though consistent with the international guidelines for treatment of TS, and could help optimize future treatment approach to TS patients in our center.
\end{abstract}

Keywords: Turner syndrome, recombinant human growth hormone, height gain, IGF-1

Address for correspondence:

Kamelia Rankova

Faculty of Medicine

Medical University of Varna

55 Marin Drinov St

9002 Varna

e-mail:kami.bachvarova@yahoo.com

Received: February 19, 2021

Accepted: March 6, 2021

\section{INTRODUCTION}

Turner syndrome (TS) is a genetic disorder that occurs in 1 in 2500 live-born girls (1). TS is caused by partial or complete loss of an X chromosome (2). The majority of affected individuals have only one $\mathrm{X}$ chromosome $(45, \mathrm{X})$, while the others display different karyotype variations, including mosaicism $(45, \mathrm{X} / 46 \mathrm{XX}$, etc.) (3). Mosaic forms are character- 
ized with milder clinical presentation and less cardiovascular and gynecological findings. (4)

The clinical manifestations of TS include growth failure, pubertal delay, and cardiovascular malformations $(2,4)$. The absence of puberty is due to ovarian dysfunction and leads to lack of the usual pubertal growth spurt, which worsens the short stature (5). Hypertension, atherosclerosis, lipid abnormalities and other cardiovascular aberrations are observed in almost $50 \%$ of TS patients and present risk factors for the development of aortic dissection and ischemic heart events (6). Typical phenotype characteristics of TS are webbed neck, low posterior hairline, abnormal dental development, broad chest (shield chest), hearing impairment, and skeletal abnormalities (4). Phenotype features, together with genetic analysis confirmation, are the standard for the diagnosis of TS (4).

Short stature is one of the main signs of the syndrome, therefore recombinant human growth hormone (rhGH) was approved by the Food and Drug Administration (FDA) for treatment in TS in 1996 (7). Treatment guidelines suggest initiation of GH as early as possible after the diagnosis with optimal dose, based on individual response to therapy (4, 8). There are still controversies about all benefits of rhGH treatment in TS, but it is undoubtedly true that it could improve height velocity and increase the final height with 15 to $20 \mathrm{~cm}$ (8).

In Bulgaria, the treatment with rhGH was introduced at the beginning of the 1990s. Initially, only one clinic in the country was authorized to prescribe rhGH free of charge. The first Bulgarian research paper for the treatment of TS children was published from Stefanova et al. in 2008 (15). In 2010, Stefanova et al. expanded these data with deeper analysis, which revealed the need of earlier diagnosis, optimal treatment regimen, and multidisciplinary observation of TS patients (16). In 2011, the Department of Pediatrics at St. Marina University Hospital, Varna was appointed as the second clinic authorized to prescribe rhGH, and later on the adjacent Varna Expert Centre of Rare Endocrine Diseases (VECRED) was nationally endorsed.

\section{AIM}

The aim of this article is to assess the results of treatment with rhGH in patients with TS for the pe- riod 2011-2020. The patients were treated and followed up at VECRED, St. Marina University Hospital, Varna.

\section{PATIENTS AND METHODS}

The design of the study is a retrospective cohort evaluation. Data for the analysis was retrieved from patients' files from 2011 to 2020 . The study included 28 children diagnosed with TS or karyotype variation of TS. The diagnosis was based on phenotype characteristics and confirmed with genetic analysis.

The following data was collected for each patient: gender, mother's and father's height $(\mathrm{cm})$, genetic variant, patient variables before the start of therapy and at each visit-chronological age, weight $(\mathrm{kg}), \mathrm{rhGH}$ dose $(\mathrm{mg} / \mathrm{kg} / \mathrm{d})$, serum IGF-1 level (ng/ $\mathrm{mL}$ ); bone age once a year (in years \pm 0.1 ), imaging study results (MRI/CT, echocardiography, abdominal echography). In some of the patients, the final height was available. All visit investigations followed the current TS guideline (4).

$\mathrm{RhGH}$ dose (mg/kg/d), height, weight, bone age and IGF-1 values were followed during the period of treatment. The gain in height $(\mathrm{Ht}) \mathrm{SDS}$ and height velocity $(\mathrm{HV})(\mathrm{cm} / \mathrm{yr})$ for every year were calculated as the difference between height at the beginning of the treatment year and a measurement made approximately 12 months later. IGF-1 modality was calculated using its values before start and at the end of the treatment year. Height SDS was calculated using CDC z-score charts adjusted for age, sex, and pubertal stage (9). Comparison with condition-specific Turner growth charts was not performed in this study.

According to the national requirements, the criteria to start rhGH therapy were the following: clinical manifestation of short stature, confirmed diagnosis of TS with genetic test, levels of IGF-1 and/or IGFBP-3 below -1SD, delayed bone age. Gonadotrophic and sex steroid hormone levels, TSH and FT4 levels, cardiovascular system, gonadal development and treatment safety parameters such as HbAlc, alkaline phosphatase, blood glucose, etc. were investigated at each visit. Criteria of exclusion were: closed epiphyseal plates, severe and active general illness, active neoplasm, allergy to rhGH. According to the health insurance requirements, all patients were followed up at least 2 times during each treatment year. 
Kamelia Rankova, Violeta Iotova, Vilhelm Mladenov et al.

All patients gave their consent for inclusion of follow-up data in the current analysis.

Data are presented as relative shares (\%), standard deviation (SD) and some variables as mean $( \pm \mathrm{SD})$ or median values. Descriptive statistics and linear regression were performed using SPSS for Windows (SPSS 19.0). Statistical significance of the results was accepted at $\mathrm{p}<0.05$ level.

\section{RESULTS}

This study included 28 children and adults (26 girls, $92.9 \%$ ), who were diagnosed with TS or karyotype variation of TS $(32.1 \%$ with $45, \mathrm{X})$ that was genetically confirmed (Table 1). They were followed-up for a total of 1071 patient-months. All patients presented with some phenotypic features of TS, shortening of the $4^{\text {th }}$ metacarpal bone of the hand in 20 (71.4\%), pectus excavatum in $4(14.2 \%)$, hearing impairment in $2(7.1 \%)$, and rhizomelic shortening of the limbs in 4 (14.2\%) being least common. Autoimmune thyroiditis was found in $6(21.4 \%)$ of the patients, and L-thyroxine at a mean starting dose of 50 $\mu \mathrm{g} / \mathrm{d}$ was introduced in all of them. Celiac disease was not detected in any of the patients.

Imaging studies were conducted in all patients diagnosed with TS. Brain aberration was found in $1(3.5 \%)$ of the performed MRI/CT of the pituitary region.

The echocardiography $(\mathrm{n}=24)$ revealed normal heart structure in 15 (53.5\%), bicuspid aortic valve in $3(10.7 \%)$, aortic valve stenosis in $2(7.1 \%)$, and other malformations in 4 (14.2\%) of the patients. The abdominal echography found normal structures in the

Table 1. Karyotype distribution among all patients with TS

\begin{tabular}{l|c} 
Karyotype & Frequency \\
45,X (incl. 45,X,20pcenh+) & $\mathbf{3 5 . 6} \%$ \\
$45, \mathrm{X} / 46, \mathrm{XY}$ & $\mathbf{1 7 . 8} \%$ \\
$45, \mathrm{X} / 46, \mathrm{XX}$ & $\mathbf{7 . 1} \%$ \\
$45, \mathrm{X} / 46, \mathrm{X}, \mathrm{i}(\mathrm{X})(\mathrm{q} 10)$ & $\mathbf{3 . 5} \%$ \\
$45, \mathrm{X}, 1 \mathrm{qh}+/ 46, \mathrm{X}, \mathrm{i}(\mathrm{X})(\mathrm{q}), 1 \mathrm{qh}+$ & $\mathbf{3 . 5} \%$ \\
$46, \mathrm{Xdel}(\mathrm{X})(\mathrm{p} 22.1) / 46, \mathrm{XX}$ & $\mathbf{3 . 5} \%$ \\
$45, \mathrm{X} / 46, \mathrm{X}, \mathrm{r}(\mathrm{X})(:: \mathrm{p} 22 \rightarrow \mathrm{q} 28)$ & $\mathbf{3 . 5} \%$ \\
$45, \mathrm{X}(61) / 46, \mathrm{X}, \mathrm{i}(\mathrm{X})(\mathrm{q} 10)(7) / 47, \mathrm{X}, \mathrm{i}(\mathrm{X})$ & $\mathbf{3 . 5} \%$ \\
(q10),i(X)(q10)(2) & $\mathbf{2 2 \%}$ \\
Other & \\
\hline
\end{tabular}

\section{Mean GH doses per year $(\mathrm{mg} / \mathrm{kg} / \mathrm{d})$}

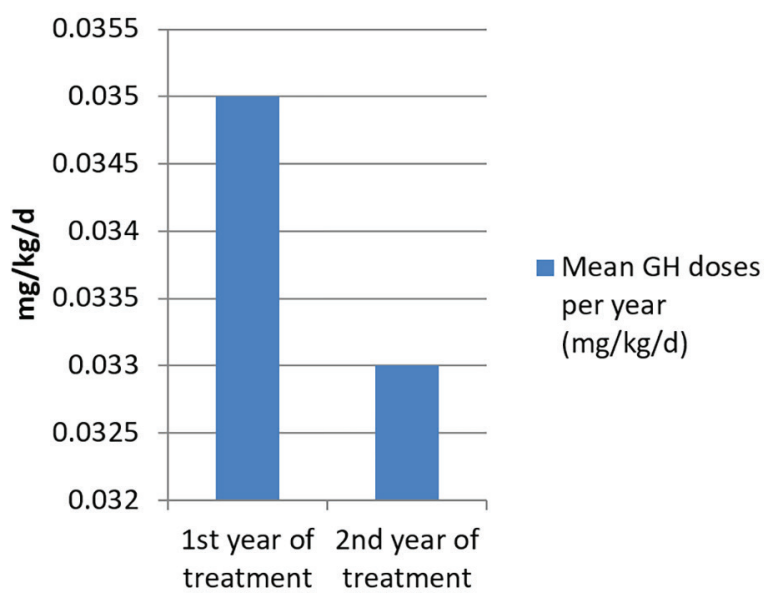

Fig. 1. Mean GH doses during the treatment of children with TS per year $(\mathrm{mg} / \mathrm{kg} / \mathrm{d})$

2 boys included in the study. No visualization of ovaries was detected in 21 (75\%), hypoplastic uterus in 11 (39.2\%), and tubular uterus in 2 (7.1\%) of the children. In 2 girls (7.1\%) the initial abdominal ultrasound found "ovaries" that were not confirmed later on MRI. Renal abnormalities (horseshoe kidney) were documented in $3(10.7 \%)$ of the patients.

Therapy with rhGH was started in $22(78.5 \%)$ patients. The other 6 patients were either above 14 years of age $(n=2)$ or below 2 years of age $(n=2)$. Two girls were diagnosed at the Center at age 7 and 10 years, they were followed for at least 1 year but have not yet started therapy with rhGH due to family noncompliance. The mean age at the start of rhGH therapy was $9.27 \pm 3.4$ years (range between 2.3 and 14.8 years). The mean starting $\mathrm{rhGH}$ dose was $0.035 \pm 0.006 \mathrm{mg} / \mathrm{kg} / \mathrm{d}$ (range $0.022-0.045 \mathrm{mg} / \mathrm{kg} / \mathrm{d}$ ), with $\mathrm{SDS}_{\text {height }}$ before the start of treatment $-2.75 \pm 1.2$ SD. Patients treated with a mean initial rhGH dose of $0.035 \pm 0.010 \mathrm{mg} /$ $\mathrm{kg} / \mathrm{d}$ achieved height gain of $\mathbf{8 . 0} \pm \mathbf{1 . 3} \mathbf{c m}(\mathrm{n}=22)$ for the $1^{\text {st }}$ year. This resulted in SDS ${ }_{\text {height }}$ at the end of the $1^{\text {st }}$ year of $-2.27 \pm 1.2 \mathrm{SD}\left(\Delta \mathrm{SDS}_{\text {height }} 0.48, \mathrm{p}=0.005\right)$. The mean rhGH dose for the $2^{\text {nd }}$ year was $0.033 \pm 0.007 \mathrm{mg} /$ $\mathrm{kg} / \mathrm{d}$ and the height gain was $\mathbf{6 . 8} \pm \mathbf{1 . 1} \mathrm{cm}(\mathrm{n}=17)$ (Fig. 1). Improvement in $\mathrm{SDS}_{\text {height }}$ was observed at the end of the $2^{\text {nd }}$ year compared to the pre-treatment values $(-2.75 \pm 1.2$ SD vs $-2.11 \pm 1.2$ SD, $\mathrm{p}<0.005)$. A great improvement was noted when SDS $_{\text {IGF } 1}$ before $(-0.74 \pm 1.1$ 
SD) and after 1st year of treatment $(1.57 \pm 1.4 \mathrm{SD})$ were compared, without exceeding $2 \mathrm{SD}(\mathrm{p}=0.001)$. In all patients, bone age advanced during treatment.

Final height was observed in 7 (25\%) of all patients included in this study. Five of them were treated with rhGH and reached SDS $_{\text {final height }}$ of $-1.32 \pm 1.5$ $\mathrm{SD}$. In the untreated patients $(\mathrm{n}=2)$ the $\mathrm{SDS}_{\text {final height }}$ was $-2.7 \pm 0.8 \mathrm{SD}, \mathrm{p}<0.05$. No diversion from the normal values of the routine biochemical blood analysis was discovered in the treated cohort.

Spontaneous puberty occurred in one patient with genetic variation $46, \mathrm{Xdel}(\mathrm{X})(\mathrm{p} 22.1) / 46, \mathrm{XX}$. In 11 (39.2\%) of the patients, hormone replacement therapy was started after the age of 11 , at a mean age of $13 \pm 1.3$ years, between 6 and 30 months after starting rhGH treatment. Treatment with oral progesterone was started in 4 (14.2\%) girls after breakthrough bleeding at a mean age of $16.2 \pm 1.4$ years.

No adverse effects and no diversion from the normal values of the routine biochemical blood analysis were registered in TS patients in our Center since 2011.

\section{DISCUSSION}

The presented study provides a detailed description of the recent diagnostic and therapeutic patterns in patients with TS at a tertiary university center in Varna, Bulgaria.

The diagnosis of TS is based on auxological parameters, clinical observation and genetic analysis. The typical phenotype characteristics of the syndrome were observed in all of the patients in the current study. In agreement with the data from the literature, $\mathrm{X}$ monosomy $(45, \mathrm{X})$ is the most common karyotype in our TS patients (3). Some other signs of TS are more rarely observed in our cohort (pectus excavatum, hearing impairment, rhizomelic shortening of the limbs) in contrast with the literature where chest deformities are described in $20 \%$, hearing loss or disturbance in $30 \%$, and limb shortening in almost $35 \%$ of the patients (4).

The initial approval of rhGH therapy from FDA was only for pituitary nanism, while nowadays it has much wider indications (isolated or multiple GHD, idiopathic short stature, Prader-Willi syndrome, Turner syndrome, children born small for gestational age without postnatal catch-up, chronic kidney injury and other syndromes and diseases)
(10). According to the international guidelines for TS (4), growth hormone alone or in combination with sex hormone replacement therapy improves the final height in TS children. Initially, rhGH was applied worldwide in TS in doses as in GH-deficient patients $(0.025 \mathrm{mg} / \mathrm{kg} / \mathrm{d})$, but now the approved international doses are between 0.050 and $0.053 \mathrm{mg} / \mathrm{kg} / \mathrm{d}$. In our study the average rhGH dose at the Center was up to $0.035 \mathrm{mg} / \mathrm{kg} / \mathrm{d}$ at the beginning in 2011, but currently there is tendency to start with a higher rhGH dose. For example, all children who started therapy in the last two years (2018-2020) had initial rhGH dose above $0.040 \mathrm{mg} / \mathrm{kg} / \mathrm{d}$, which corresponds with the Bulgarian health insurance requirements of 0.035$0.045 \mathrm{mg} / \mathrm{kg} / \mathrm{d}$. Higher rhGH dose could be considered only in cases with poor adult height prognosis (11). Although the rhGH dosing was lower than the upper limit approved by the international guidelines, the children demonstrated good height gain and the observed growth velocity corresponded to the data from some same-period international studies (8).

Geffner et al. (7) and Kesler et al. (12) suggest that optimal results of rhGH treatment could be achieved when treatment is started at age 4-6 years and before 12-13 years at the latest. In our cohort the therapy with rhGH started at similar age range, but still the syndrome is rarely recognized by the general practitioners and pediatricians, and often these patients reach pediatric endocrinologist at an age when is too late for rhGH treatment. Stockholm et al. (3) report mean age at diagnosis of 15.1 years, in contrast to the review of Takeda et al. (17) where the mean age of diagnosis is 6.6 years, but still one third of the children started therapy after the age of 12 . In Bulgaria, the study of Stefanova et al. (16) revealed mean age at diagnosis of 9.9 years, but initiation of therapy was after 13 years of age. Stefanova et al. also confirmed that still many children with TS remain undiagnosed until the age of 12-15 years.

According to Grimberg et al. (10), measurement of IGF-1 levels could be used as a monitoring tool of the response to rhGH dose changes. In our study, the best $\triangle \mathrm{SDS}_{\mathrm{IGF}-1}$ was observed between baseline and the end of the $1^{\text {st }}$ year of treatment. The change of SDS ${ }_{\text {IGF-1 }}$ was above 1.0 SD, which is a sign of good response to rhGH treatment in our cohort. There are still not enough studies to evaluate the safe upper limit of serum IGF-1 concentrations in TS. Therefore, if an ad- 
Kamelia Rankova, Violeta Iotova, Vilhelm Mladenov et al.

equate height gain is observed with normal levels of IGF-1, no supraphysiological levels should be maintained. However, the treatment with higher rhGH doses may carry a risk of long-term adverse effects $(4,10)$. The adjustment of the rhGH dose should be individualized and the lowest dose with demonstrated efficacy should be used.

The primary aim of rhGH treatment of TS children is to improve the growth velocity and final height (13). Ranke et al. (13) ascertain in their study that the best response to rhGH therapy can be achieved in the first year of treatment and height velocity in the next years is relatively lower. According to the review of Li et al. (8), in TS the height gain in the first two years of rhGH therapy is greatest similar to GH deficiency conditions. In our study, the best height velocity is observed in the first treatment year and declines in the subsequent years.

Other beneficial effects of rhGH concern body composition and cognitive skills (14). Still there are some controversies about the duration of therapy and the dosing of rhGH, sometimes due to financial limitations (13). Therefore, the treatment pattern should be in consent with the individual response to rhGH and the lowest rhGH dose that leads to optimal growth rate should be applied as already mentioned.

The international guidelines (4) recommend initiation of hormone replacement therapy (HRT) between 11-12 years of age. Soriano-Guillen et al. (18) report of age at start of HRT between 14.6 and 16 years of age, while Irzyniec et al. (19) start HRT between 8 and 14 years of age. Published Bulgarian data from Stefanova et al. for the treatment of TS children documented starting of HRT at the age of 13.5-15 years. More than one third (39.2\%) of our patients received HRT after at least 1.6 years of GH treatment and at relatively younger age.

Some strengths of this study are the homogeneous and strictly followed cohort of patients and the duration of follow-up of almost 10 years.

As limitation we could point to the fact that the patients were treated with different dosing patterns applied at the Center during these years as well as the relatively small study cohort.

\section{CONCLUSION}

Data from the current study for growth velocity and health indicators are close to the results for the benefits of rhGH treatment in TS patients from the literature. The present analysis would help to optimize the treatment approach to TS patients at our Center in order to attain better final height in these children, mostly through applying higher rhGH doses during the initial treatment phases together with strict monitoring of safety, and optimizing timing and pattern of hormone replacement therapy

\section{Acknowledgement}

We would like to thank all participants in the study, their families and the staff of First Pediatric Clinic and supporting laboratories at St. Marina University Hospital in Varna.

\section{REFERENCES}

1. Baxter L, Bryant J, Cave CB, Milne R. Recombinant growth hormone for children and adolescents with Turner syndrome. Cochrane Database Syst Rev. 2007;(1):CD003887. doi: 10.1002/14651858. CD003887.pub2.

2. Woelfle J, Lindberg A, Aydin F, Ong KK, Camacho-Hubner C, Gohlke B. Secular trends on birth parameters, growth, and pubertal timing in girls with Turner syndrome. Front Endocrinol (Lausanne). 2018;9:54. doi: 10.3389/fendo.2018.00054

3. Stochholm K, Juul S, Juel K, Naeraa RW, Gravholt $\mathrm{CH}$. Prevalence, incidence, diagnostic delay, and mortality in Turner syndrome. J Clin Endocrinol Metab. 2006;91(10):3897-902. doi: 10.1210/ jc.2006-0558.

4. Gravholt C, Andersen N, Conway G, Dekkers O, Geffner M, Klein K, et al. Clinical practice guidelines for the care of girls and women with Turner syndrome: proceedings from the 2016 Cincinnati International Turner Syndrome Meeting. Eur J Endocrinol. 2017;177(3):G1-G70. doi: 10.1530/ EJE-17-0430.

5. Spiliotis BE. Recombinant human growth hormone in the treatment of Turner syndrome. Ther Clin Risk Manag. 2008;4(6):1177-83. doi: 10.2147/tcrm. s1440.

6. Mavinkurve $\mathrm{M}, \mathrm{O}$ O'Gorman CS. Cardiometabolic and vascular risks in young and adolescent girls with Turner syndrome. BBA Clin. 2015;3:304-9. doi: 10.1016/j.bbacli.2015.04.005.

7. Reh CS, Geffner ME. Somatotropin in the treatment of growth hormone deficiency and Turner syndrome in pediatric patients: a review. Clin Pharmacol. 2010;2:111-22. doi: 10.2147/CPAA.S6525. 
8. Li P, Cheng F, Xiu L. Height outcome of the recombinant human growth hormone treatment in Turner syndrome: a meta-analysis. Endocr Connect. 2018; 7(4):573-83. doi: 10.1530/EC-18-0115.

9. https://www.cdc.gov/growthcharts/data_tables.htm

10. Grimberg A, DiVall S, Polychronakos C, Allen D, Cohen L, Quintos J, et al. Guidelines for growth hormone and insulin-like growth factor-1 treatment in children and adolescents: Growth hormone deficiency, idiopathic short stature, and primary insulin-like growth factor-1 deficiency. Horm Res Paediatr. 2016;86(6):361-97. doi: $10.1159 / 000452150$.

11. Polak M, Konrad D, Tønnes Pedersen B, Puras G, Šnajderová M. Still too little, too late? Ten years of growth hormone therapy baseline data from the NordiNet ${ }^{\oplus}$ International Outcome Study. J Pediatr Endocrinol Metab. 2018;31(5):521-32. doi: 10.1515/ jpem-2017-0489.

12. Kesler SR. Turner syndrome. Child Adolesc Psychiatr Clin N Am. 2007;16(3):709-22. doi: 10.1016/j. chc.2007.02.004.

13. Ranke MB, Lindberg A, Chatelain P, Wilton P, Cutfield W, Albertsson-Wikland K, et al. Prediction of long-term response to recombinant human growth hormone in Turner syndrome: development and validation of mathematical models. KIGS International Board. Kabi International Growth Study. J Clin Endocrinol Metab. 2000;85(11):4212-8. doi: 10.1210/jcem.85.11.6976.
14. Blankenstein $\mathrm{O}$, Snajderova M, Blair J, Pournara E, Pedersen BT, Petit IO. Real-life GH dosing patterns in children with GHD, TS or born SGA: a report from the NordiNet ${ }^{\circledast}$ International Outcome Study. Eur J Endocrinol. 2017;177(2):145-55. doi: 10.1530/ EJE-16-1055.

15. Stefanova, E. Treatment of short stature in Turner syndrome with recombinant human growth hormone. Pediatria. 2008. Suppl: 40-3. (in Bulgarian).

16. Stefanova E, Peneva L. Recombinant human growth hormone together with low dose estrogens stimulate growth and pubertal development in girls with Turner syndrome. Pediatria. 2010. 1 Suppl:49-53. (in Bulgarian).

17. Takeda A, Cooper K, Bird A, Baxter L, Frampton GK, Gospodarevskaya E, et al. Recombinant human growth hormone for the treatment of growth disorders in children: a systematic review and economic evaluation. Health Technol Assess. 2010;14(42):1-209, iii-iv. doi: 10.3310/hta14420.

18. Soriano-Guillen L, Coste J, Ecosse E, Léger J, Tauber M, Cabrol S, et al. Adult height and pubertal growth in Turner syndrome after treatment with recombinant growth hormone. J Clin Endocrinol Metab. 2005;90(9):5197-204. doi: 10.1210/ jc.2005-0470.

19. Irzyniec T, Jez W, Lepska K, Maciejewska-Paszek I, Frelich J. Childhood growth hormone treatment in women with Turner syndrome - benefits and adverse effects. Sci Rep. 2019;9(1):15951. doi: 10.1038/ s41598-019-52332-0. 